\title{
External shame, loneliness, psychological distress, and well-being: insights from the Turkish adaptation of the Other as Shamer Scale-2
}

\author{
Begum Satici (D) $1 \cdot A, B, C, D, E, F$, M. Engin Deniz (D) $2 \cdot B, E$ \\ 1: Artvin Coruh University, Artvin, Turkey \\ 2: Yildiz Technical University, Istanbul, Turkey
}

BACKGROUND

In this paper, we examine the Other as Shamer Scale-2 (OAS-2), a unidimensional and brief scale to directly assess external shame. In three studies with three independent samples of a Turkish university, we present evidence for OAS-2 validity with respect to well-being outcomes (subjective happiness, flourishing, and subjective well-being) and psychological distress outcomes (depression, anxiety, stress, and loneliness) through direct comparisons with existing measures.

\section{PARTICIPANTS AND PROCEDURE}

In Study $1(N=311)$, confirmatory factor analyses, measurement invariance across gender, and Item Response Theory (IRT) were examined. In Study $2(N=380)$, criterion-related validities of the OAS- 2 were analyzed. In Study $3(N=252)$, incremental validity was examined using PROCESS. Also, internal consistency, composite reliability, and temporal reliability $(n=89)$ of the OAS-2 were investigated.

\section{RESULTS}

In Study 1, confirmatory factor analyses supported the unidimensionality of the measure. The results provide sup- port for measurement invariance across gender. All item scores fit the IRT model and were fit with ordered, progressing hierarchies in their step difficulties. In Study 2, criterion-related validity for the OAS-2 was demonstrated through positive correlations with loneliness, and negative correlations with subjective happiness and flourishing. In Study 3 , findings indicated the mediation impact of external shame on well-being via psychological distress. The OAS-2 showed satisfactory reliability coefficients.

\section{CONCLUSIONS}

Overall, the OAS-2 proved to be a valuable and reliable tool, which presents a short form to measure external shame. In addition, it was observed that the OAS-2 was related to both well-being and psychological distress.

\section{KEY WORDS}

external shame; well-being; psychological distress; measurement invariance; item response theory

CORRESPONDING AUthor - Begum Satici, Ph.D., Faculty of Education, Artvin Coruh University, 08000 Artvin, Turkey, e-mail: begum@artvin.edu.tr

authors' Contribution - A: Study design - B: Data collection - C: Statistical analysis - D: Data interpretation . E: Manuscript preparation · F: Literature search · G: Funds collection

to Cite this ARTICLE - Satici, B., \& Deniz, M. E. (2020). External shame, loneliness, psychological distress, and well-being: insights from the Turkish adaptation of the Other as Shamer Scale-2. Current Issues in Personality Psychology, 8(2), 154-167. 


\section{BACKGROUND}

Shame is a powerful, self-conscious emotion that emerges from the experience of being seen as defective, inadequate or powerless by others. Gilbert's model "The Evolutionary and Biopsychosocial Model of Shame" provides significant information about the formation and development of shame (Gilbert, 2009, 2010). According to this model, from the moment they are born, individuals need to create positive emotions about themselves in the minds of others. Therefore, the way individuals experience interpersonal relationships at an early age has a very important effect on how we think we exist in the minds of others. Accordingly, shame emerges from our complex, evolved mental abilities to be aware of "how we exist for others" and to make predictions regarding what they think and feel about us (Gilbert, 2002, 2003). Also, shame has been described as both an intrapsychic and an interpersonal emotion (Tangney, 1995). On the other hand, shame conveys a strong message of self-abasement (Giner-Sorolla, Kamau, \& Castano, 2010). In addition, shame, which develops as a system which regulates psychobiological reactions, may lead to rejection, ostracism, put-downs and even persecution (Saggino et al., 2017). From this point of view, the concern of being seen as inferior to others in an unattractive way can be experienced (Gilbert, 2007). For this reason, shame can be accepted as an indicator or stimulus of potential social damage.

Shame can be divided in two categories: internal and external (Gilbert, 1998, 2003; Gilbert \& Procter, 2006). Internal shame is defined as a negative self-evaluation focusing on personal mistakes and perceived deficits (Gilbert, 1998). The individual maintains severe self-criticism processes (Gilbert, 2007). In this context, internal shame is the tendency to see oneself as a worthless person (Marta-Simões, Ferreira, \& Mendes, 2016). On the other hand, external shame is the shame we experience when we believe we are held negatively in the minds of others (Matos, Pinto-Gouveia, \& Costa, 2013). According to another definition, external shame includes the negative opinions of the self as seen from the perspective of others (Kim, Thibodeau, \& Jorgensen, 2011). In external shame, the attentions of individuals are focused on the minds of others and their behaviors are orientated toward trying to influence their images in the minds of others (Matos et al., 2013). In other words, in external shame, the attention is focused on the minds of others with an aim to imagine what is in their minds and thus exhibit behaviors meant to change their opinions (Balsamo et al., 2015).

EXTERNAL SHAME, LONELINESS, WELL-BEING, AND PSYCHOLOGICAL DISTRESS

For shame, the term "sleeper of psychopathology" is used (Lewis, 1987, p. 1). Not only are there efforts to examine what may elicit shame, but there is also a growing interest in investigating the association between shame and individuals' well-being, including psychological distress.

Because shame is a self-disapproving, devastating and painful experience, it makes individuals vulnerable to psychological distress (Lee, Anderson, \& KlimesDougan, 2016). Moreover, shame includes subjective emotions which make individuals feel small, insignificant, helpless and worthless, which can cause them to experience distress (Kim et al., 2011). Therefore, shamed individuals can be passive in the face of psychological distress such as depression, anxiety, and stress. In their longitudinal research, Cunha and her colleagues (2016) found that external shame strongly predicted higher levels of depression. Also, it was specified that shame was a factor in increasing depression, according to the modelling (Lee et al., 2016; Mereish \& Poteat, 2015; Thoresen, Aakvaag, Strøm, Wentzel-Larsen, \& Birkeland, 2018). In a meta-analysis study, external shame was associated with increasing depression (Kim et al., 2011). In addition, it was reported in other studies that shamed individuals experienced more anxiety, and stress (Pineles, Street, \& Koenen, 2006; Mensinger, Tylka, \& Calamari, 2018; Thomson \& Jaque, 2018). Lastly, Castilho and her colleagues (2017) determined that external shame could directly increase depression, anxiety, and stress. Therefore, we hypothesized that external shame may have a positive relation with psychological distress (i.e. depression, anxiety, and stress).

There is expected to be a negative relationship between well-being and shame. Shame can reduce wellbeing because it is an unpleasant and painful emotion (Cibich, 2016). Similarly, shame is a negative emotion which decreases well-being (Cibich, Woodyatt, \& Wenzel, 2016). Experiences with shame can negatively affect self-engagement, social comparison processes, subsequent self-esteem, and emotional wellbeing. In studies, the negative relationship between shame and well-being is emphasized (e.g., Cavalera et al., 2017; Choma, Shove, Busseri, Sadava, \& Hosker, 2009; Kelly \& Carter, 2013). In addition, shame decreases well-being according to the model presented by Varghese (2015). In fact, shame can negatively affect the well-being of individuals by leaving them unprotected against forms of psychological distress such as depression, anxiety, etc. (Clapton, Williams, \& Jones, 2018). Other researchers have also revealed that shame has a negative relationship with life satisfaction and happiness (e.g., Bugay \& Demir, 2011; Sousa et al., 2019). Based on these explanations, we also hypothesized that there would be a negative relationship between shame and well-being.

Because external shame may lead to disengagement and self-effacement, it can cause individuals to feel lonely and isolated (Thoresen et al., 2018). In addition, because shamed individuals can be anxious about social assessment, potential rejections or regressions, 
they can withdraw from social interactions because of confidence issues (Breggin, 2015; Clapton et al., 2018; Kaufman, 2004). Furthermore, due to shame's potential for preventing the establishment of close relationships, individuals can have higher levels of loneliness (Teroni \& Deonna, 2008). Similarly, shamed individuals can feel lonely because they experience feelings of worthlessness about being engaged with others (Jordan, 2004). In addition, conceptual and empirical works emphasize that shame can increase loneliness (e.g., Mereish \& Poteat, 2015; Thoresen et al., 2018; Rostami \& Jowkar, 2016). Therefore, we hypothesized that external shame and loneliness could be positively related to each other based on both theoretical and empirical research results.

\section{MEASUREMENT OF EXTERNAL SHAME}

The Other as Shamer Scale (OAS) is commonly used to measure external shame. The OAS was developed by Allan, Gilbert, and Goss (1994) and Goss, Gilbert, and Allan (1994) based on the Internal Shame Scale of Cook (1994). In the first OAS to be developed, there are 18 items, and the items contain statements starting with "Other people see me as..." Validity studies were conducted with university students, and a threefactor structure was revealed (Goss et al., 1994). Although the OAS is three-dimensional (inferiority, emptiness, and mistakes), it is understood that studies are frequently conducted through an examination of the total external shame score (e.g., Gilbert \& Miles, 2000; Matos et al., 2013; Matos, Pinto-Gouveia, Gilbert, Duarte, \& Figueiredo, 2015).

It can be stated that the validity and the reliability of the OAS have been tested in different populations up to the present. For example, Balsamo and colleagues (2015) confirmed the structure of the OAS in an Italian sample. Similarly, the OAS has been adapted and used in the British (Wood \& Irons, 2017), Portuguese (Matos, Pinto-Gouveia, \& Duarte, 2012), Greek (Kotrotsiou et al., 2017), and Scottish (Laithwaite et al., 2009) cultures.

Recently, an abbreviated form of the OAS (OAS-2) was developed (Matos et al., 2015). The OAS-2 consists of eight items selected from the OAS. As a result of the OAS-2's confirmatory factor analysis, its one-dimensional structure was approved. It was found that acceptable internal consistency had a significant relationship with internal shame, psychopathology, and anger. Therefore, a valid, reliable and economic measurement tool for evaluating external shame emerged (Matos et al., 2015). The psychometric strength of the OAS-2 was proven in Italian university students (Saggino et al., 2017), Portuguese adolescents (Cunha, Xavier, Cherpe, \& Gouveia, 2017) and Portuguese children (Benevides, da Motta, Sousa, Caldeira, \& Carvalho, 2016).

\section{PURPOSE OF THE CURRENT STUDY}

Although shame is a universal experience (MartaSimões et al., 2016), the concept can differ according to cultures (Gilbert, 1998, 2003). Although the Other as Shamer Scale-2 (OAS-2) is consistently used by researchers, the studies regarding its adaptation to other populations and its psychometric characteristics are not sufficient.

Most of the studies examining the validity and reliability of the OAS-2 were carried out in a westernindividualist culture (Balsamo et al., 2015; Kotrotsiou et al., 2017; Laithwaite et al., 2009; Matos et al., 2015; Saggino et al., 2017). Therefore, in a collectivist culture, a measurement tool that can assess external shame is lacking. Hence, the study of external shame will contribute to a measurement tool that can be used in intercultural studies, and thus, to the conceptual development of shame.

Furthermore, although exploratory factor analysis (EFA) and confirmatory factor analysis (CFA), as well as concurrent, convergent and divergent validity, and internal and temporal reliability assessment, have been performed in the psychometric characteristics of the OAS-2 up to the present, its incremental, Item Response Theory (IRT) and composite reliability have not been carried out. Moreover, although measurement invariance across gender was conducted in the adolescent community (via independent sampling of referred and forensic samples), measurement invariance across gender was not tested in university students. Finally, the psychometric studies of the OAS-2 were conducted on a single participant group. Therefore, we aimed to carry out three different studies in this research. In Study 1, the OAS-2 was examined with CFA, measurement invariance, IRT and internal, composite and temporal reliability. In Study 2, the criterion-related validity of the OAS- 2 was evaluated with loneliness and well-being. In Study 3, the incremental validity of the OAS-2 was evaluated with the model examining the mediating roles of depression, anxiety, and stress in the relationship between external shame and well-being.

\section{STUDY 1}

The original Other as Shamer Scale-2 from Matos and colleagues (2015) was translated into Turkish by three experts using the parallel blind technique. Then, backtranslation was done according to Brislin's (1980) suggestion. Subsequently, the translation forms were discussed with doctoral students and the final version of the Turkish OAS-2 was obtained.

In Study 1, the construct validity of the Turkish OAS-2 was examined with CFA and measurement invariance. In addition, Item Response Theory analyses were conducted to check item validity. After the 
Table 1

Participant demographics

\begin{tabular}{lcccccccc}
\hline \multirow{2}{*}{ Sample } & \multicolumn{2}{c}{ Gender } & \multicolumn{3}{c}{ Age } & \multicolumn{3}{c}{ Socioeconomic status } \\
\cline { 2 - 8 } & Female & Male & $M$ & $S D$ & Range & Low & Medium & High \\
\hline Study 1 & $159(51)$ & $152(49)$ & 20.04 & 1.90 & $18-30$ & $71(23)$ & $166(53)$ & $74(24)$ \\
Study 2 & $202(53)$ & $178(47)$ & 20.45 & 2.05 & $18-26$ & $102(27)$ & $169(45)$ & $109(29)$ \\
Study 3 & $181(51)$ & $171(49)$ & 20.14 & 1.98 & $18-27$ & $91(26)$ & $177(50)$ & $84(24)$ \\
Test-retest & $47(53)$ & $42(47)$ & 19.96 & 1.81 & $18-24$ & $18(20)$ & $49(55)$ & $22(25)$ \\
\hline
\end{tabular}

Note. Information on gender and socioeconomic status is presented as $n(\%)$.

construct validity and IRT of the scale, Cronbach's $\alpha$, composite reliability, and test-retest were assessed in this study.

\section{PARTICIPANTS}

Three hundred eleven volunteer university students (159 females and 152 males) between ages 18 and 30 years $(M=20.04, S D=1.90)$ were recruited. With regard to class levels, $27 \%$ were freshmen, $29.9 \%$ sophomore, $21.9 \%$ junior, and $21.2 \%$ senior. Table 1 shows the detailed participants' demographics in all studies.

In Study 1, a new participant group was formed to examine the Turkish OAS-2's test-retest reliability in order to investigate the degree to which the scale reflects a stable predisposition. This group consisted of 89 students. The age of the participants ranged from 18 to 24 years $(M=19.96, S D=1.81)$.

\section{PROCEDURE}

The data were collected via the paper-pencil questionnaire format in the classroom environment. Written informed consent was obtained from the students before participation. In this respect, the questionnaire package was distributed only to volunteer students.

We performed CFA using AMOS Graphics to validate the factor structure of the Turkish OAS-2. As suggested in the literature (e.g., Hu \& Bentler, 1999; Kline, 2015; Marsh, Hau, \& Wen, 2004), we considered that goodness-of fit index (GFI), normed fit in$\operatorname{dex}(\mathrm{NFI})$, and confirmatory fit index $(\mathrm{CFI}) \geq .90$, root mean square error of approximation (RMSEA) and standardized root-mean-square residual $(\mathrm{SRMR}) \leq .08$ were indicative of acceptable fit.

We also evaluated the factor structure for measurement invariance by gender to assess the equivalence of factor structure across female and male subjects. In this respect, configural, metric, scalar, and strict invariance analyses were tested. As suggested in the previous research literature (Chen, 2007; Cheung \& Rensvold, 2002), $\triangle \mathrm{CFI}<.010$ and $\triangle \mathrm{RMSEA}<.015$ can be considered as indicating measurement invariance across different groups.

Lastly, we assessed the discrimination, difficulty, and informativeness of the scale with the Item Response Theory (IRT; Chalmers, 2012). In addition, IRT provides more detailed and reliable information at the individual and item level than Classical Test Theory. Within the IRT analysis, we used the item characteristic curve function and Graded Response Model, because of the polytomous nature (more than two answer categories) of the measure. IRT analyses were carried out with Stata 14.2.

\section{RESULTS}

We conducted a CFA using a maximum likelihood estimator to test the adequacy of the Turkish OAS-2 model and confirm the previously proposed Matos and colleagues' OAS-2 model. Regarding the fit statistics, the chi-square statistic was significant, probably due to the size of the sample (Hair, Black, Babin, Anderson, $\&$ Tatham, 2014), but the ratio $\chi^{2} / d f\left(\chi^{2} / d f=2.81 \leq 5\right)$, the SRMR $(.039 \leq .08)$, the RMSEA $(.076 \leq .08)$, the GFI $(.955 \geq .90)$, the NFI $(.947 \geq .90)$, and the CFI $(.965 \geq .90)$ were well inside the limits that allow the model to be accepted. All standardized factor loadings for the items were significant $(p<.001)$, ranging from .54 (item 1$)$ to .80 (item 6) (Table 2).

\section{MEASUREMENT INVARIANCE}

After the confirmation of the Turkish OAS-2, the scale was examined across gender. First, the CFA of the scale was made separately for female and male subjects. The results showed that the scale provided an adequate fit among both males $\left[\chi^{2}(20\right.$, $n=122)=42.56, p<.05 ; \mathrm{GFI}=.935 ; \mathrm{NFI}=.904 ;$ $\mathrm{CFI}=.946 ; \mathrm{SRMR}=.052 ; \mathrm{RMSEA}=.086]$ and females $\left[\chi^{2}(20, n=159)=48.21, p<.05 ; \mathrm{GFI}=.930 ; \mathrm{NFI}=.926\right.$; $\mathrm{CFI}=.955 ;$ SRMR $=.044 ;$ RMSEA $=.084]$. Then, tests of configural, metric, scalar, and strict invariance were performed. The results are presented in Table 3. 
As can be seen in Table 3, the analysis of measurement invariance supported both configural and metric invariance $(\triangle \mathrm{CFI}=.004 ; \triangle \mathrm{RMSEA}=.002)$ of the Turkish OAS-2 across gender, indicating that Turkish OAS-2 items have the same meaning for males and females. On the other hand, scalar $(\triangle \mathrm{CFI}=.076 ; \Delta \mathrm{RMSEA}=.076)$

Table 2

CFA results of the Turkish OAS-2

\begin{tabular}{lccc}
\hline Item & $\begin{array}{c}\text { Standardized } \\
\text { factor loading }\end{array}$ & $\begin{array}{c}\text { Error } \\
\text { variance }\end{array}$ & $R^{2}$ \\
\hline 1 & .54 & .71 & .43 \\
2 & .69 & .39 & .63 \\
3 & .61 & .61 & .65 \\
4 & .62 & .56 & .62 \\
5 & .79 & .26 & .38 \\
6 & .80 & .25 & .37 \\
7 & .79 & .30 & .48 \\
8 & .65 & .49 & .30 \\
\hline
\end{tabular}

and strict invariance $(\triangle \mathrm{CFI}=.012 ; \triangle \mathrm{RMSEA}=.004)$ models were not supported due to both goodness-of-fit and $\triangle \mathrm{CFI}-\triangle \mathrm{RMSEA}$ values. In this regard, the use of scalar and strict invariance values should be cautious.

\section{ITEM RESPONSE THEORY}

IRT, which is a popular method for evaluating educational tools, is currently being increasingly used in personality measures (e.g., Colledani, Anselmi, \& Robusto, 2019; Coskun \& Kara, 2019). These basic aspects of the IRT parameters can be visually shown in an S-shape curve known as the item characteristic curve (ICC). ICC analysis was performed with a Graded Response Model (GRM) because the Turkish OAS-2 has a five-point Likert type scale. Results of the IRT are presented in Figure 1 and Table 4.

As shown in Table 4, all $a$ values are higher than 1.0. According to Baker (2001), an $a$ value $>1.0$ is considered highly discriminant. Therefore, IRT results indicated that items of the Turkish OAS-2 are capable of discriminating better performers from poor performers and possessing adequate item difficulty.

Table 3

Fit indices of gender invariance

\begin{tabular}{lccccccccc}
\hline Invariance & $\chi^{2}$ & $d f$ & GFI & NFI & CFI & RMSEA & SRMR & $\Delta C F I$ & $\Delta$ RMSEA \\
\hline Males & 42.56 & 20 & .935 & .904 & .946 & .08 & .05 & - & - \\
Females & 48.20 & 20 & .930 & .926 & .955 & .08 & .04 & - & - \\
Configural invariance & 89.83 & 40 & .930 & .955 & .974 & .08 & .04 & - & - \\
Metric invariance & 102.99 & 47 & .923 & .949 & .971 & .08 & .06 & .004 & .002 \\
Scalar invariance & 316.37 & 62 & .776 & .867 & .895 & .16 & .21 & .076 & .076 \\
Strick invariance & 376.42 & 71 & 743 & .851 & .883 & .17 & .28 & .012 & .004 \\
\hline
\end{tabular}

Note. $d f$ - degrees of freedom; GFI - goodness-of-fit index; NFI - normed fit index; CFI - confirmatory fit index; RMSEA - root mean square error of approximation.

Table 4

Item Response Theory parameter estimates for the Turkish OAS-2

\begin{tabular}{lccccc}
\hline Item & \multicolumn{5}{c}{ Item parameter estimates } \\
\cline { 2 - 5 } & $a$ & $b_{1}$ & $b_{2}$ & $b_{3}$ & $b_{4}$ \\
\hline 1 & 1.59 & -0.95 & 0.41 & 1.92 & 3.27 \\
2 & 2.17 & 0.02 & 1.21 & 2.14 & 3.63 \\
3 & 1.66 & -0.44 & 0.81 & 2.07 & 3.23 \\
4 & 1.85 & 0.01 & 1.17 & 2.13 & 3.15 \\
5 & 2.96 & 0.53 & 1.36 & 2.16 & 2.75 \\
7 & 3.37 & 0.56 & 1.42 & 2.06 & 2.46 \\
8 & 2.76 & 0.30 & 1.28 & 1.89 & 2.62 \\
\hline
\end{tabular}



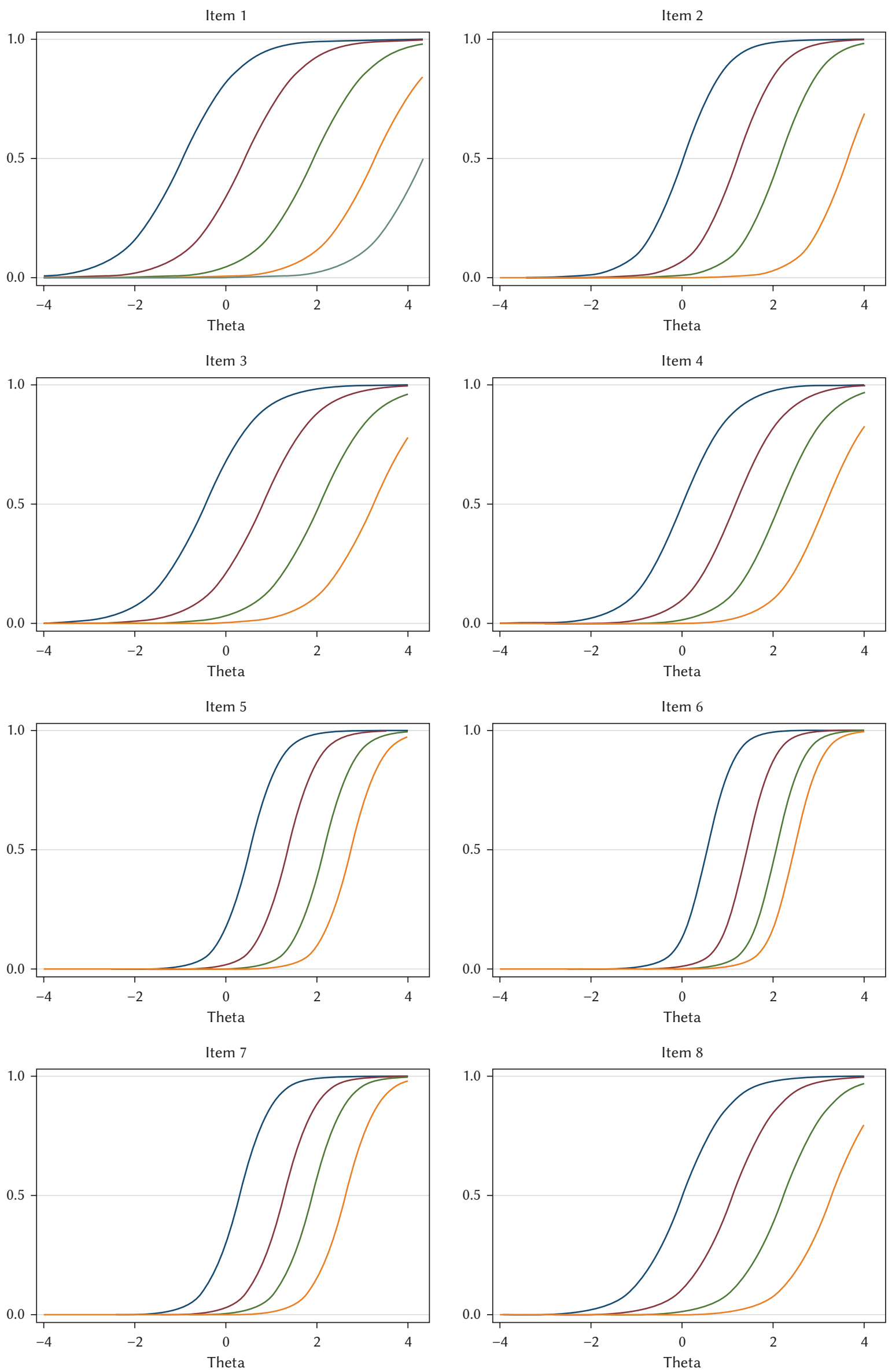

Figure 1. Item characteristics curve for the Turkish OAS-2. 


\section{RELIABILITY}

Cronbach's $\alpha$, composite reliability (CR), and test-retest reliability were checked for the internal and the temporal reliabilities. The Turkish OAS-2 was reapplied to students with a 28-day interval for test-retest reliability. The result showed that the internal consistency reliabilities were highly acceptable $(\alpha=.88$ and $\mathrm{CR}=.88$ ). In addition, the test-retest analysis revealed that the Turkish OAS-2 showed temporal reliability with a correlation coefficient of .86 .

\section{STUDY 2}

Study 2 was conducted with an aim to evaluate the criterion-related validity of the Turkish OAS-2. Data were collected on the Turkish OAS-2 along with three standardized validity measures whose details are given below in the measures section.

\section{PARTICIPANTS}

A total of 380 (202 female and 178 male) individuals participated in Study 2. They were aged 18-26 (average age: 20.45 years, $S D=2.05$ ). With regard to class levels, $25.8 \%$ were freshmen, $28.2 \%$ sophomore, $23.7 \%$ junior, and $22.4 \%$ senior. Demographics are summarized in Table 1.

\section{MEASURES}

In addition to the Turkish OAS-2 $(\alpha=.89)$, the UCLA Loneliness Scale, the Subjective Happiness Scale, and the Flourishing Scale were added in this study. Information about the scales is presented below.

The UCLA Loneliness Scale (ULS-8) by Hays and DiMatteo (1987) comprises 8 items (e.g., "There is no one I can turn to") in uni-dimensional structure. Participants responded on a four-point Likert scale ranging from 1 (I never feel this way) to 4 (I often feel this way). The scores that can be obtained in the ULS-8

Table 5

Correlations of the Turkish OAS-2 and the other scales

\begin{tabular}{lccc}
\hline \multirow{2}{*}{ Item } & \multicolumn{3}{c}{ Turkish OAS-2 } \\
\cline { 2 - 4 } & $r$ & $\begin{array}{c}\text { Lower } \\
95 \% \mathrm{Cl}\end{array}$ & $\begin{array}{c}\text { Upper } \\
\text { 9 }\end{array}$ \\
\hline Loneliness $\mathrm{Cl}$ \\
Subjective happiness & -.36 & -.43 & -.28 \\
Flourishing & -.39 & -.49 & -.29 \\
\hline Note. $\mathrm{Cl}$ - confidence interval. & &
\end{tabular}

vary between 8 and 32 . Rising scores indicate that the feeling of loneliness also increases. The ULS- 8 was adapted to Turkish by Dogan, Akinci-Cotok, and Gocet-Tekin (2011) from the original version. The psychometric characteristics of the Turkish ULS-8 are satisfactory $(\alpha=.72$; GFI $=.97$, AGFI $=.94, \mathrm{CFI}=.94$, and RMSEA = .066; Dogan et al., 2011). In the current research, Cronbach's $\alpha$ coefficient was .82.

The Subjective Happiness Scale (SHS) by Lyubomirsky and Lepper (1999) comprises 4-items in uni-dimensional structure. Participants responded on a fourpoint Likert scale ranging from 1 (I never feel this way) to 4 (I often feel this way). A sample item is: "In general, I consider myself." The scores that can be obtained in the SHS vary between 4 and 28. Rising scores indicate that the level of subjective happiness also increases. The SHS was adapted to Turkish by Akin and Satici (2011) from the original version. The psychometric characteristics of the Turkish SHS are satisfactory $(\alpha=.70 ; \mathrm{NFI}=.99, \mathrm{CFI}=1.00, \mathrm{RFI}=.98, \mathrm{GFI}=1.00$, AGFI $=.99$, and SRMR $=.015$; Akin \& Satici, 2011). In the current research, Cronbach's $\alpha$ coefficient was .73.

The Flourishing Scale (FS) by Diener and colleagues (2010) comprises 8-items in uni-dimensional structure. Participants responded on a seven-point Likert scale ranging from 1 (strongly disagree) to 7 (strongly agree). A sample item is: "I actively contribute to the happiness and well-being of others." The scores that can be obtained in the FS vary between 8 and 56 . Rising scores indicate a person with many psychological resources and strengths. The FS was adapted to Turkish by Telef (2013) from the original version. The psychometric characteristics of the Turkish FS are satisfactory $(\alpha=.80 ; \mathrm{GFI}=.96, \mathrm{NFI}=.94$, RFI $=.92$, $\mathrm{CFI}=.95, \mathrm{IFI}=.95, \mathrm{SRMR}=.04$; Telef, 2013). In the current research, Cronbach's $\alpha$ coefficient was .88 .

\section{PROCEDURE}

The same data collection process in Study 1 was also used in Study 2. Criterion-related criterion validity was assessed by computing Pearson's correlations of the Turkish OAS-2 with the criterion measures as validity coefficients. Correlational analyses were conducted using IBM SPSS Statistics 22.

\section{RESULTS}

The results of the correlational analyses are presented in Table 5. The analyses showed significant positive correlations between the Turkish OAS-2 and loneliness $(r=.48, p<.001)$. On the other hand, the Turkish OAS-2 is significantly and negatively correlated with subjective happiness, $r=-.36, p<.001$. A significant negative correlation was also observed between the Turkish OAS-2 and flourishing, $r=-.39, p<.001$. 


\section{STUDY 3}

The incremental validity of the Turkish OAS-2 was also tested in a process model linking external shame to subjective well-being via depression, anxiety, and stress. Prior studies indicated that external shame may increase psychological distress (e.g., Castilho et al., 2017; Kim et al., 2011), and also may reduce well-being (Cibich et al., 2016; Varghese, 2015). Moreover, relevant literature showed that shame may reduce wellbeing via psychological distress (e.g., Clapton et al., 2018). Therefore, we tested the meditational model with external shame as an independent variable, depression, anxiety, and stress as mediator variables and subjective well-being as a dependent variable.

\section{PARTICIPANTS}

A total of 352 (181 female and 171 male) individuals participated in Study 3. They were aged 18-27 (average age: 20.14 years, $S D=1.98$ ). With regard to class levels, $27 \%$ were freshmen, $25.6 \%$ sophomore, $22.4 \%$ junior, and $25 \%$ senior. Demographics are summarized in Table 1.

\section{MEASURES}

In addition to the Turkish OAS-2 $(\alpha=.89)$, the Depression, Anxiety, and Stress Scale, the Positive and Negative Affect Schedule, and the Satisfaction with Life Scale were used in this study. Information about the scales is presented below.

The Depression Anxiety Stress Scale (DASS) by Lovibond and Lovibond (1995) comprises 42 items in three-dimensional structure: depression (e.g., "I felt that I had lost interest in just about everything"), anxiety (e.g., "I feared that I would be 'thrown' by some trivial but unfamiliar task"), and stress (e.g., "I was in a state of nervous tension"). Participants responded on a four-point Likert scale ranging from 0 (did not apply to me at all) to 3 (applied to me very much, or most of the time). The DASS was adapted to Turkish by Akin and Çetin (2007) from the original version. The psychometric characteristics of the Turkish DASS are satisfactory $(\alpha=.90, .92$, and .92 , respectively). In the current research, Cronbach's $\alpha$ coefficient values were $.91, .88$ and .89 for depression, anxiety, and stress, respectively.

The Positive and Negative Affect Schedule (PANAS) by Watson, Clark, and Tellegen (1988) comprises 20 items in two-dimensional structure: positive affect and negative affect. Participants responded on a fivepoint Likert scale ranging from 1 (very slightly or not at all) to 5 (extremely). The PANAS was adapted to Turkish by Gençöz (2000) from the original version. The psychometric characteristics of the Turkish
PANAS are satisfactory ( $\alpha=.82$ and .70, respectively). In the current research, Cronbach's $\alpha$ coefficient values were .80 and .79 for positive affect and negative affect, respectively.

The Satisfaction with Life Scale (SWLS) by Diener, Emmons, Larsen, and Griffin (1985) comprises 5-items in uni-dimensional structure. Participants responded on a seven-point Likert scale ranging from 1 (strongly disagree) to 7 (strongly agree). A sample item is "The conditions of my life are excellent." The scores that can be obtained in the SWLS vary between 5 and 35 . Rising scores indicate that the level of life satisfaction also increased. The SWLS was adapted to Turkish by Durak, Senol-Durak, and Gençöz (2010) from the original version. The psychometric characteristics of the Turkish SWLS are satisfactory $(\alpha=.81$; CFI $=.99$, IFI $=.99$, TLI $=.98$, SRMR $=.020$, and RMSEA = .043; Durak et al., 2010). In the current research, Cronbach's $\alpha$ coefficient was .80 .

\section{PROCEDURE}

Mediation was tested in IBM SPSS Statistics 22 using a macro developed by Hayes (PROCESS version 3.2; Hayes, 2018) in order to check the incremental validity of the Turkish OAS-2. This macro uses regression path analyses to estimate direct and indirect effects of a predictor variable on an independent variable. We first examined whether external shame (independent variable) was associated with subjective well-being (dependent variable) and depression, anxiety, and stress (DAS; mediators). Next, we examined whether the effect of external shame on subjective well-being (positive affect + life satisfaction - negative affect) could be mediated by psychological distress such as depression, anxiety, and stress. Bias-corrected 95\% bootstrapped confidence intervals (CIs) of this indirect effect with 10000 iterations were acquired. CIs that do not contain 0 indicate the presence of a mediation effect. This procedure is suggested for its accuracy in estimating confidence intervals and for control of type 1 error rates (MacKinnon, Lockwood, \& Williams, 2004).

\section{RESULTS}

Findings for the regression pathways and the direct and indirect effects examined for mediation are presented in Figure 2 and Table 6.

Figure 2 shows the effect of external shame on subjective well-being through depression, anxiety, and stress. The total indirect effect is significant for external shame on subjective well-being $(B=-1.33$, $S E=.12,95 \% \mathrm{CI}=-1.59$ to -1.12$)$. When depression, anxiety and stress are entered into the model as mediators, the direct effect of external shame on subjective well-being is significantly reduced, suggesting 


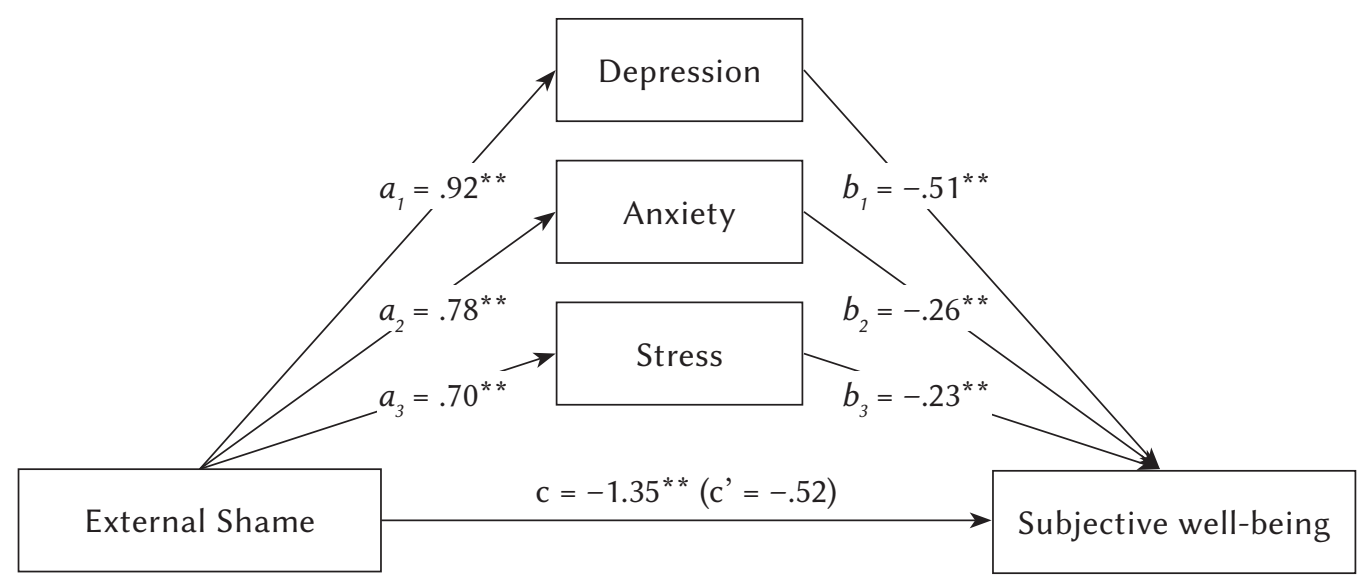

Figure 2. Effect of external shame on subjective well-being through depression, anxiety, and stress.

Table 6

Parameters and 95\% CIs for incremental validity of the Turkish OAS-2

\begin{tabular}{|c|c|c|c|c|}
\hline Path & Estimate & $S E$ & Lower $95 \% \mathrm{Cl}$ & Upper $95 \% \mathrm{Cl}$ \\
\hline \multicolumn{5}{|l|}{ Direct } \\
\hline OAS-2 $\rightarrow$ Depression & .92 & .07 & .78 & 1.07 \\
\hline OAS-2 $\rightarrow$ Anxiety & .78 & .07 & .64 & .92 \\
\hline OAS-2 $\rightarrow$ Stress & .70 & .08 & .54 & .86 \\
\hline OAS-2 $\rightarrow$ SWB & -.52 & .12 & -.76 & -.28 \\
\hline Depression $\rightarrow$ SWB & -.51 & .12 & -.75 & -.27 \\
\hline Anxiety $\rightarrow$ SWB & -.26 & .13 & -.51 & -.01 \\
\hline Stress $\rightarrow$ SWB & -.23 & -.10 & -.42 & -.03 \\
\hline \multicolumn{5}{|l|}{ Indirect effect } \\
\hline OAS-2 $\rightarrow$ Depression $\rightarrow$ SWB & -.47 & .12 & -.71 & -.24 \\
\hline OAS-2 $\rightarrow$ Anxiety $\rightarrow$ SWB & -.21 & .09 & -.39 & -.04 \\
\hline OAS-2 $\rightarrow$ Stress $\rightarrow$ SWB & -.16 & .07 & -.31 & -.03 \\
\hline Total effect & -1.33 & .12 & -1.59 & -1.12 \\
\hline
\end{tabular}

Note. OAS-2 - Other as Shamer Scale-2; SWB - subjective well-being; SE - standard error; Cl - confidence interval.

a partial mediating role. Of the proposed mediators, the specific indirect effects are significant for depression $\left(B_{a 1}=.92, S E=.07,95 \% \mathrm{CI}=0.78-1.06\right)$, anxiety $\left(B_{a 2}=.78, S E=.07,95 \% \mathrm{CI}=.64-.92\right)$, and stress $\left(B_{a 3}=.70, S E=.08,95 \% \mathrm{CI}=.54-.86\right)$. Consistent with expectations, the Turkish OAS-2 supported incremental validity and it predicted relevant constructs independent of other factors that have been shown to be statistically associated with these constructs.

\section{DISCUSSION}

The OAS-2 is a tool widely used in the world for measuring external shame. It has been adapted into various languages, and its validity and reliability have been previously examined. In this study, the psychometric properties of the OAS-2 in Turkish university students were evaluated. Three separate studies were conducted in line with this purpose, and results on external shame were obtained.

According to the CFA conducted in Study 1, the OAS-2 was found to have acceptable goodness of fit indices. The CFA results indicated that all goodness of fit indices were at an acceptable level and that standardized factor loadings were significant. Therefore, the unidimensional structure of the Turkish OAS-2 was verified. Although the first version of the OAS involved a three-dimensional structure, the unidimensional structure was used in later studies (e.g., Gilbert \& Miles, 2000; Matos et al., 2013). Matos and colleagues (2015), however, found that there was also 
a unidimensional structure in the OAS-2 development study. Similarly, in the Italian sample (Saggino et al., 2017), the OAS-2's unidimensional structure had good fit indices. Thus, the Turkish OAS-2 has both replicated its original unidimensional structure and verified the theoretical model of external shame.

In the configural and metric invariance analysis, the unidimensional structure proposed for gender yielded similar results in both females and males. This was consistent with the results showing that Portuguese adult females and males do not differ significantly and were partially invariant across boys and girls, who presented similar levels of shame in the long and short forms of the OAS (Matos et al., 2015; Vagos, da Silva, Brazao, Rijo, \& Gilbert, 2016). These invariance results also parallel the Italian, university students' version of the OAS-2 (Saggino et al., 2017). On the other hand, scalar and strict invariance analyses did not support the model in this present study, which, nevertheless, was also partially in parallel with the Italian version. Thus, the conceptualization of the external shame structure seems to be partially similar for both genders, as assessed by the OAS-2, given the results of configural and metric invariance.

No previous study in which OAS was examined using the Item Response Theory was encountered. There are two approaches: IRT and classical test theory (CTT). CTT has a major drawback. The summed scores are sequential, and statistical inferences based on sequence scores may be invalid because of the assumption that raw scores should be considered as a range scale (Hobart, Cano, Zajicek, \& Thompson, 2007; Jafari, Bagheri, Ayatollahi, \& Soltani, 2012). For example, CTT treats a five-point (never, seldom, sometimes, often, always) Likert-type scale as an interval scale, and scores five points between zero and four. However, the differences between the five points may not be equal. In contrast, the IRT uses a logistic equation to predict participants' underlying capabilities and item challenges. Thus, the interval-level measurement of each participant's external shame, and the interval-level measurements of item challenges, are determined (Chang, Lin, Gronholm, \& Wu, 2018). The characteristics and validity of the items are examined in IRT, and the fitness of the items is determined. Therefore, according to the IRT results of the Turkish OAS-2, the item challenges and characteristics were appropriate. Researchers (Embretson \& Reise, 2000; Reeve \& Fayers, 2005) agree when using the IRT model with a five-point Likert-type scale, and 250 participants can produce a reasonable estimate, which indicates that the IRT results obtained are sufficient for the OAS-2.

Within the scope of Study 2, the criterion-related validity of the Turkish OAS-2 was discussed. The findings indicated that the OAS- 2 was significant in the positive association with loneliness and in the negative association with subjective happiness and flourishing, which are indicators of wellbeing. The relevant literature suggested that shame is consistently and positively correlated with loneliness (e.g., Mereish \& Poteat, 2015; Thoresen et al., 2018; Rostami \& Jowkar, 2016) and has a negative relationship with well-being (e.g., Choma et al., 2009; Kelly \& Carter, 2013). Therefore, this study's results parallel the literature and support the criterion-related validity of the OAS- 2 .

Study 3 tested the incremental validity of the OAS-2, examining the mediation role of psychological distress in the relationship between external shame and well-being. The study found that external shame may increase depression, anxiety, and stress and that these increases may weaken an individual's well-being. The literature supports this result (e.g., Castilho et al., 2017; Lee et al., 2016; Mereish \& Poteat, 2015; Thoresen et al., 2018; Varghese, 2015). Kim and colleagues (2011) indicated that external shame may lead to psychological distress. Furthermore, external shame may also reduce well-being via psychological distress dimensions such as negative emotions, and feelings of helplessness and worthlessness. In addition, psychological distress being instrumental between shame and well-being may be explained by the fact that shamed individuals are passive against distress. In addition, it can be deduced that shame for mediation may make individuals vulnerable to psychological distresses, such as depression, anxiety, etc., and, hence, their well-being can be adversely affected (Clapton et al., 2018).

Finally, the internal, composite, and temporal reliability of the Turkish OAS-2 was examined. The reliability coefficient of OAS-2 in its original study was found to be .82 . In addition, the OAS-2's internal consistency was .89 for Italian university students (Saggino et al., 2017), .92 for Portuguese adolescents (Cunha et al., 2017), and .85 for children (Benevides et al., 2016). The reliability coefficients in this research are similar $(.88, .89$, and .89 , Study 1,2 , and 3 , respectively). However, the composite reliability of OAS-2 has not been previously discussed. CR in this study is sufficient, with .88. Temporal reliability was also studied for Portuguese adolescents (.73; Cunha et al., 2017) and Portuguese children (.55; Benevides et al., 2016). In this present research temporal reliability was found to be .86. All the reliability coefficients found in this study are observed to be similar to coefficients of the OAS- 2 in other cultures. The findings also indicate that the criterion of being over .70 for reliability, as recommended by Nunnally (1978), is overcompensated. Therefore, it should be stated that the Turkish OAS-2 is a reliable measurement tool.

\section{LIMITATIONS}

In this study, where strong psychometric results of the Turkish OAS-2 have emerged, there were some 
limitations. Firstly, the research was conducted with non-clinical, university students. Therefore, the findings should not be generalized to the clinical population. However, in future studies, the discriminant validity of the OAS-2 in clinical and non-clinical populations should be examined. Secondly, the Turkish OAS-2 is based on self-reported information. Because shame experiences may show partial bias, participants may perform differently on some items when self-reporting (Saggino et al., 2017). Therefore, self-report measures can be integrated with a neurophysiological markers analysis in order to provide a comprehensive assessment of shame (Vagos et al., 2016). Finally, the gender invariance of the OAS-2 was examined. However, subsequent studies, as Saggino and colleagues (2017) suggested, should address the measurement invariance of OAS-2 in different cultures.

\section{CONCLUSIONS}

The Turkish OAS-2 was shown to have validity and reliability, according to the findings of three different studies using advanced techniques such as measurement invariance, incremental validity, and item response theory. The results indicate that the Turkish OAS-2 can be used to measure external shame in a short time. Although other studies on the OAS-2's measurement power are needed, this research supports the idea that external shame is a useful tool for evaluating individuals' personality, psychological distress, and well-being. The OAS-2 cannot be used as a tool that gives a general evaluation of individuals' personality, but to evaluate the particular predisposition of imaging negative beliefs towards the self in the mind of others.

\section{RefERENCES}

Akin, A., \& Çetın, B. (2007). The Depression Anxiety and Stress Scale (DASS): The study of validity and reliability. Educational Sciences: Theory and Practice, 7, 260-268.

Akin, A., \& Satici, S. A. (2011). Subjective Happiness Scale: a study of validity and reliability. Sakarya University Journal of Education Faculty, 21, 65-77.

Allan, S., Gilbert, P., \& Goss, K. (1994). An exploration of shame measures - II: Psychopathology. Personality and Individual Differences, 17, 719-722. https://doi.org/10.1016/0191-8869(94)90150-3

Baker, F. B. (2001). The basics of Item Response Theory. Second edition. Retrieved from https://eric. ed.gov/?id=ED458219

Balsamo, M., Macchia, A., Carlucci, L., Picconi, L., Tommasi, M., Gilbert, P., \& Saggino, A. (2015). Measurement of external shame: an inside view.
Journal of Personality Assessment, 97, 81-89. https://doi.org/10.1080/00223891.2014.947650

Benevides, J., da Motta, C., Sousa, M., Caldeira, S. N., \& Carvalho, C. (2016). The psychometric properties of the brief Other as Shamer Scale for Children (OAS-C): Preliminary validation studies in a sample of Portuguese children. BMC Health Services Research, 16, Suppl. 3.

Breggin, P. R. (2015). The biological evolution of guilt, shame and anxiety: a new theory of negative legacy emotions. Medical Hypotheses, 85, 17-24. https://doi.org/10.1016/j.mehy.2015.03.015

Brislin, R. W. (1980). Translation and content analysis of oral and written material. In H. C. Triandis \& J. W. Berry (Eds.), Handbook of cross-cultural psychology (pp. 389-444). Boston, MA: Allyn and Bacon.

Bugay, A., \& Demir, A. (2011). Psychometric properties of the Turkish version of Trait Shame and Guilt Scale. Eurasian Journal of Educational Research, 45, 17-30.

Castilho, P., Pinto-Gouveia, J., \& Duarte, J. (2017). Two forms of self-criticism mediate differently the shame-psychopathological symptoms link. Psychology and Psychotherapy: Theory, Research and Practice, 90, 44-54. https://doi.org/10.1111/papt.12094

Cavalera, C., Pagnini, F., Zurloni, V., Piazzini, D. B., Realdon, O., Castelnuovo, G., Todisco P., \& Molinari, E. (2017). Erratum to: Shame proneness and eating disorders: a comparison between clinical and non-clinical samples. Eating and Weight Disorders, 22, 379. https://doi.org/10.1007/s40519-0170376-y

Chalmers, R. P. (2012). Mirt: a multidimensional item response theory package for the $\mathrm{R}$ environment. Journal of Statistical Software, 48, 1-29. https://doi. org/10.18637/jss.v048.i06

Chang, C. C., Lin, C. Y., Gronholm, P. C., \& Wu, T. H. (2018). Cross-validation of two commonly used self-stigma measures, Taiwan versions of the Internalized Stigma Mental Illness Scale and Self-Stigma Scale-Short, for people with mental illness. Assessment, 25, 777-792. https://doi. org/10.1177/1073191116658547

Chen, F. F. (2007). Sensitivity of goodness of fit indexes to lack of measurement invariance. Structural Equation Modeling, 14, 464-504. https://doi. org/10.1080/10705510701301834

Cheung, G. W., \& Rensvold, R. B. (2002). Evaluating goodness-of-fit indexes for testing measurement invariance. Structural Equation Modeling, 9, 233255. https://doi.org/10.1207/S15328007SEM0902_5

Choma, B. L., Shove, C., Busseri, M. A., Sadava, S. W., \& Hosker, A. (2009). Assessing the role of body image coping strategies as mediators or moderators of the links between self-objectification, body shame, and well-being. Sex Roles, 61, 699-713. https://doi.org/10.1007/s11199-009-9666-9 
Cibich, M. (2016). Teaching and learning guide for: Moving beyond "Shame is bad": How a functional emotion can become problematic. Social and Personality Psychology Compass, 10, 575-578. https:// doi.org/10.1111/spc3.12270

Cibich, M., Woodyatt, L., \& Wenzel, M. (2016). Moving beyond "shame is bad": How a functional emotion can become problematic. Social and Personality Psychology Compass, 10, 471-483. https:// doi.org/10.1111/spc3.12263

Clapton, N. E., Williams, J., \& Jones, R. S. (2018). The role of shame in the development and maintenance of psychological distress in adults with intellectual disabilities: a narrative review and synthesis. Journal of Applied Research in Intellectual Disabilities, 31, 343-359. https://doi.org/10.1111/jar.12424

Colledani, D., Anselmi, P., \& Robusto, E. (2019). Using multidimensional item response theory to develop an abbreviated form of the Italian version of Eysenck's IVE questionnaire. Personality and Individual Differences, 142, 45-52. https://doi. org/10.1016/j.paid.2019.01.032

Cook, D. R. (1994). Internalized Shame Scale: Technical manual. North Tonawanda, NY: Multi-Health Systems, Inc.

Coskun, K., \& Kara, C. (2019). Moral identity test (MIT) for children: Reliability and validity. Psicologia: Reflexão e Crítica, 32, 7. https://doi.org/ 10.1186/s41155-019-0120-9

Cunha, M., Almeida, R., Cherpe, S., Simões, S., \& Marques, M. (2016). A longitudinal approach to the contribution of trauma and external shame on depressive symptoms in adolescence. European Psychiatry, 33, S129-S130. https://doi.org/10.1016/j. eurpsy.2016.01.188

Cunha, M., Xavier, A. M. D. J., Cherpe, S., \& Gouveia, J. P. (2017). Assessment of shame in adolescents: The Other as Shamer Scale. Psicologia: Teoria e Pesquisa, 33, 1-9. https://doi.org/10.1590/0102.3772e3336

Diener, E. D., Emmons, R. A., Larsen, R. J., \& Griffin, S. (1985). The Satisfaction with Life Scale. Journal of Personality Assessment, 49, 71-75. https:// doi.org/10.1207/s15327752jpa4901_13

Diener, E., Wirtz, D., Tov, W., Kim-Prieto, C., Choi, D. W., Oishi, S., \& Biswas-Diener, R. (2010). New well-being measures: Short scales to assess flourishing and positive and negative feelings. Social Indicators Research, 97, 143-156. https://doi. org/10.1007/s11205-009-9493-y

Dogan, T., Cotok, N. A., \& Gocet-Tekin, E. (2011). Reliability and validity of the Turkish version of the UCLA Loneliness Scale (ULS-8) among university students. Procedia - Social and Behavioral Sciences, 15, 2058-2062. https://doi.org/10.1016/j. sbspro.2011.04.053

Durak, M., Senol-Durak, E., \& Gencoz, T. (2010). Psychometric properties of the Satisfaction with Life Scale among Turkish university students, correc- tional officers, and elderly adults. Social Indicators Research, 99, 413-429. https://doi.org/10.1007/ s11205-010-9589-4

Embretson, S. E., \& Reise, S. P. (2000). Item response theory for psychologists. Mahwah, NJ: Lawrence Erlbaum Associates.

Gençöz, T. (2000). Pozitif ve negatif duygu ölçeği: Geçerlik ve güvenirlik çalışması [Positive and Negative Affect Schedule: a study of validity and reliability]. Türk Psikoloji Dergisi, 15, 19-26.

Gilbert, P. (1998). What is shame? Some core issues and controversies. In P. Gilbert \& B. Andrews (Eds.), Shame: Interpersonal behaviour, psychopathology and culture (pp. 3-36). New York: Oxford University Press.

Gilbert, P. (2002). Body shame: a biopsychosocial conceptualisation and overview, with treatment implications. In P. Gilbert \& J. Miles (Eds.), Body shame: Conceptualisation, research and treatment (pp. 3-54). London: Routledge.

Gilbert, P. (2003). Evolution, social roles, and the differences in shame and guilt. Social Research, 70, 1205-1230.

Gilbert, P. (2007). The evolution of shame as a marker for relationship security. In J. L. Tracy, R. W. Robins, \& J. P. Tangney (Eds.), The self-conscious emotions: Theory and research (pp. 283-309). New York: Guilford.

Gilbert, P. (2009). Introducing compassion-focused therapy. Advances in Psychiatric Treatment, 15, 199-208. https://doi.org/10.1192/apt.bp.107.005264

Gilbert, P. (2010). Compassion-focused therapy. New York: Routledge.

Gilbert, P., \& Miles, J. N. (2000). Sensitivity to social put-down: Its relationship to perceptions of social rank, shame, social anxiety, depression, anger and self-other blame. Personality and Individual Differences, 29, 757-774. https://doi.org/10.1016/S01918869(99)00230-5

Gilbert, P., \& Procter, S. (2006). Compassionate mind training for people with high shame and self-criticism: Overview and pilot study of a group therapy approach. Clinical Psychology and Psychotherapy, 13, 353-379. https://doi.org/10.1002/cpp.507

Giner-Sorolla, R., Kamau, C. W., \& Castano, E. (2010). Guilt and shame through recipients' eyes: The moderating effect of blame. Social Psychology, 41, 88-92. https://doi.org/10.1027/1864-9335/a000013

Goss, K., Gilbert, P., \& Allan, S. (1994). An exploration of shame measures - I: The Other as Shamer Scale. Personality and Individual Differences, 17, 713-717. https://doi.org/10.1016/0191-8869(94)90149-X

Hair, J. F., Black, W. C., Babin, B. J., Anderson, R. E., \& Tatham, R. L. (2014). Multivariate data analysis. Pearson new international edition. Harlow: Pearson Education Limited.

Hayes, A. F. (2018). Partial, conditional, and moderated moderated mediation: Quantification, inference, 
and interpretation. Communication Monographs, 85, 4-40. https://doi.org/10.1080/03637751.2017.1352100

Hays, R. D., \& DiMatteo, M. R. (1987). A short-form measure of loneliness. Journal of Personality Assessment, 51, 69-81. https://doi.org/10.1207/s15327752jpa5101_6

Hobart, J. C., Cano, S. J., Zajicek, J. P., \& Thompson, A. J. (2007). Rating scales as outcome measures for clinical trials in neurology: Problems, solutions, and recommendations. The Lancet. Neurology, 6, 1094-1105. https://doi.org/10.1016/S1474-4422(07) 70290-9

Hu, L. T., \& Bentler, P. M. (1999). Cutoff criteria for fit indexes in covariance structure analysis: Conventional criteria versus new alternatives. Structural Equation Modeling, 6, 1-55. https://doi.org/ 10.1080/10705519909540118

Jafari, P., Bagheri, Z., Ayatollahi, S. M. T., \& Soltani, Z. (2012). Using Rasch rating scale model to reassess the psychometric properties of the Persian version of the PedsQL TM 4.0 Generic Core Scales in school children. Health and Quality of Life Outcomes, 10, 27. https://doi.org/10.1186/1477-7525-10-27

Jordan, J. V. (2004). Shame and humiliation: From isolation to relational transformation. In J. V. Jordan, M. Walker, \& L. M. Hartling (Eds.), The complexity of connection (pp. 103-128). New York: Guilford Press.

Kaufman, G. (2004). The psychology of shame: Theory and treatment of shame-based syndromes. New York: Springer Publishing Company.

Kelly, A. C., \& Carter, J. C. (2013). Why self-critical patients present with more severe eating disorder pathology: The mediating role of shame. British Journal of Clinical Psychology, 52, 148-161. https:// doi.org/10.1111/bjc.12006

Kim, S., Thibodeau, R., \& Jorgensen, R. S. (2011). Shame, guilt, and depressive symptoms: a metaanalytic review. Psychological Bulletin, 137, 68-96. https://doi.org/10.1037/a0021466

Kline, R. B. (2015). Principles and practice of structural equation modeling (4th ed.). New York: Guilford Publications.

Kotrotsiou, S., Tsoumani, E., Kotrotsiou, E., Gouva, M., Dragioti, E., \& Paralikas, T. (2017). Problems of investigation of immigrants' students and their relation to psychopathology. European Psychiatry, 41, S624. https://doi.org/10.1016/j.eurpsy.2017.01.1008

Laithwaite, H., O’Hanlon, M., Collins, P., Doyle, P., Abraham, L., Porter, S., \& Gumley, A. (2009). Recovery after psychosis (RAP): a compassion focused programme for individuals residing in high security settings. Behavioural and Cognitive Psychotherapy, 37, 511-526. https://doi.org/10.1017/ S1352465809990233

Lee, C. Y. S., Anderson, J. R., \& Klimes-Dougan, B. (2016). Potentially traumatic experiences, academic performance, and psychological distress: The role of shame. Journal of Counseling and Development, 94, 41-50. https://doi.org/10.1002/jcad.12060 Lewis, H. B. (1987). Introduction: Shame - the "sleeper" in psychopathology. In H. B. Lewis (Ed.), The role of shame in symptom formation (pp. 1-28). Hillsdale, NJ: Erlbaum.

Lovibond, P. F., \& Lovibond, S. H. (1995). The structure of negative emotional states: Comparison of the Depression Anxiety Stress Scales (DASS) with the Beck Depression and Anxiety Inventories. Behaviour Research and Therapy, 33, 335-343. https:// doi.org/10.1016/0005-7967(94)00075-U

Lyubomirsky, S., \& Lepper, H. S. (1999). A measure of subjective happiness: Preliminary reliability and construct validation. Social Indicators Research, 46, 137-155. https://doi.org/10.1023/A:1006824100041

MacKinnon, D. P., Lockwood, C. M., \& Williams, J. (2004). Confidence limits for the indirect effect: Distribution of the product and resampling methods. Multivariate Behavioral Research, 39, 99-128. https://doi.org/10.1207/s15327906mbr3901_4

Marsh, H. W., Hau, K. T., \& Wen, Z. (2004). In search of golden rules: Comment on hypothesis-testing approaches to setting cutoff values for fit indexes and dangers in overgeneralizing Hu and Bentler's (1999) findings. Structural Equation Modeling, 11, 320-341. https://doi.org/10.1207/s15328007sem1103_2

Marta-Simões, J., Ferreira, C., \& Mendes, A. L. (2016). Exploring the effect of external shame on body appreciation among Portuguese young adults: The role of self-compassion. Eating Behaviors, 23, 174179. https://doi.org/10.1016/j.eatbeh.2016.10.006

Matos, M., Pinto-Gouveia, J., \& Costa, V. (2013). Understanding the importance of attachment in shame traumatic memory relation to depression: The impact of emotion regulation processes. Clinical Psychology and Psychotherapy, 20, 149-165. https://doi.org/10.1002/cpp.786

Matos, M., Pinto-Gouveia, J., \& Duarte, C. (2012). When I don't like myself: Portuguese version of the internalized shame scale. The Spanish Journal of Psychology, 15, 1411-1423. https://doi.org/10.5209/ rev_SJOP.2012.v15.n3.39425

Matos, M., Pinto-Gouveia, J., Gilbert, P., Duarte, C., \& Figueiredo, C. (2015). The Other as Shamer Scale-2: Development and validation of a short version of a measure of external shame. Personality and Individual Differences, 74, 6-11. https://doi. org/10.1016/j.paid.2014.09.037

Mensinger, J. L., Tylka, T. L., \& Calamari, M. E. (2018). Mechanisms underlying weight status and healthcare avoidance in women: a study of weight stigma, body-related shame and guilt, and healthcare stress. Body Image, 25, 139-147. https://doi. org/10.1016/j.bodyim.2018.03.001

Mereish, E. H., \& Poteat, V. P. (2015). A relational model of sexual minority mental and physical health: The negative effects of shame on relation- 
ships, loneliness, and health. Journal of Counseling Psychology, 62, 425-437. https://doi.org/10.1037/ cou0000088

Nunnally, J. C. (1978). Psychometric theory. New York: McGraw-Hill Book Company.

Pineles, S. L., Street, A. E., \& Koenen, K. C. (2006). The differential relationships of shame-proneness and guilt-proneness to psychological and somatization symptoms. Journal of Social and Clinical Psychology, 25, 688-704. https://doi.org/10.1521/ jscp.2006.25.6.688

Reeve, B. B., \& Fayers, P. (2005). Applying item response theory modeling for evaluating questionnaire item and scale properties. In P. Fayers \& R. D. Hays (Eds.), Assessing quality of life in clinical trials: Methods of practice (pp. 55-73). New York: Oxford University Press.

Rostami, S., \& Jowkar, B. (2016). The relationship between guilt and shame feelings with the dimensions of loneliness: The moderating effect of gender. International Journal of Behavioral Sciences, 10, 72-76.

Saggino, A., Carlucci, L., Sergi, M. R., D’Ambrosio, I., Fairfield, B., Cera, N., \& Balsamo, M. (2017). A validation study of the psychometric properties of the Other as Shamer Scale-2. SAGE Open, 7. https://doi.org/10.1177/2158244017704241

Sousa, M., Cabral, J., Benevides, J., da Motta, C., Carvalho, C. B., \& Peixoto, E. (2019). Life satisfaction: Study of the predictors in a mixed Portuguese sample. Psychology, Community \& Health, 8, 14-26. https://doi.org/10.5964/pch.v8i1.245

Tangney, J. P. (1995). Shame and guilt in interpersonal relationships. In J. P. Tangney \& K.W. Fischer (Eds.), Self-conscious emotions: The psychology of shame, guilt, embarrassment, and pride (pp. 114-139). New York: Guilford Press.

Telef, B. B. (2013). Psikolojik iyi oluş ölçeği: Türkçeye uyarlama, geçerlik ve güvenirlik çalışması [The adaptation of psychological well-being into Turkish: a validity and reliability study]. Hacettepe Üniversitesi Eğitim Fakültesi Dergisi, 28, 374-384.

Teroni, F., \& Deonna, J. A. (2008). Differentiating shame from guilt. Consciousness and Cognition, 17, 725740. https://doi.org/10.1016/j.concog.2008.02.002

Thomson, P., \& Jaque, S. (2018). Shame and anxiety: The mediating role of childhood adversity in dancers. Journal of Dance Medicine and Science, 22, 100108. https://doi.org/10.12678/1089-313X.22.2.100

Thoresen, S., Aakvaag, H. F., Strøm, I. F., WentzelLarsen, T., \& Birkeland, M. S. (2018). Loneliness as a mediator of the relationship between shame and health problems in young people exposed to childhood violence. Social Science and Medicine, 211, 183-189. https://doi.org/10.1016/j.socscimed.2018.06.002

Vagos, P., da Silva, D. R., Brazao, N., Rijo, D., \& Gilbert, P. (2016). Dimensionality and measurement invariance of the Other as Shamer Scale across diverse adolescent samples. Personality and Individual Differences, 98, 289-296. https://doi.org/10.1016/j. paid.2016.04.046

Varghese, M. E. (2015). Attachment to God and psychological well-being: Shame, guilt, and self-compassion as mediators. Doctoral dissertation, Purdue University, West Lafayette, IN. Retrieved from https:// docs.lib.purdue.edu/open_access_dissertations/578 Watson, D., Clark, L. A., \& Tellegen, A. (1988). Development and validation of brief measures of positive and negative affect: the PANAS scales. Journal of Personality and Social Psychology, 54, 10631070. https://doi.org/10.1037//0022-3514.54.6.1063

Wood, L., \& Irons, C. (2017). Experienced stigma and its impacts in psychosis: The role of social rank and external shame. Psychology and Psychotherapy: Theory, Research and Practice, 90, 419-431. https://doi.org/10.1111/papt.12127 